\title{
Special Topic on Conservation Biology of Endangered Wildlife pushes conservation studies
}

\author{
FANG ShengGuo* \& ZHU Ying \\ The Key Laboratory of Conservation Biology for Endangered Wildlife of the Ministry of Education, State Conservation Center for Gene \\ Resources of Endangered Wildlife, College of Life Sciences, Zhejiang University, Hangzhou 310058, China
}

In recent years Chinese Science Bulletin has published some work focused on environment, biodiversity and sustainability, etc. [1-10]. This has promoted the follow-up and indepth research efforts, and to some extent, has accelerated the development of conservation studies on endangered animals and plants.

The 12 papers [11-22], published in the Special Topic on Conservation Biology of Endangered Wildlife of Chinese Science Bulletin on August 20, 2011, give some good examples. The genotyping methods of He et al. [11] have been applied in identifying paternity and social relationships of the golden snub-nosed monkey in the Qinling Mountains of central China. The conservation studies of Xiang et al. [15] have drawn the attention of the scientific and technological management bureaus and thus obtained financial assistance to start the genome sequencing project of the golden snub-nosed monkey. On the basis of paternity testing techniques developed by Li et al. [16], the China Research and Conservation Center for the Giant Panda (Wolong) is carrying out the pedigree construction of captive giant pandas. Finally, the Chinese alligator's cell line built by Zeng et al. [19] has been successfully applied in chromosome assignment of the gender-related genes using fluorescence in situ hybridization (FISH). These genes were identified from the Chinese alligator genome sequencing project, which was initiated by Fang ShengGuo's team in cooperation with the Beijing Genomics Institute (BGI-Shenzhen).

As a result, the special focus of Chinese Science Bulletin will attract more prominent scientists' papers in the future and gradually boost different disciplines. If things continue this way, as one of flagship journals in China, Chinese Science Bulletin will greatly push forward in-depth development of China's science and technology studies.

*Corresponding author (email: sgfanglab@zju.edu.cn)
1 Yang H, Meng X X, Yu L, et al. Advances in research of mammalian vomeronasal pheromone perception and genetic components unique to vomeronasal signal transduction pathway. Chin Sci Bull, 2010, 55: 2473-2478

2 Liu Z L, Peng C H, Xiang W H, et al. Application of artificial neural networks in global climate change and ecological research: An overview. Chin Sci Bull, 2010, 55: 3853-3863

3 Niu Y F, Feng Y L, Xie J L, et al. Noxious invasive Eupatorium adenophorum may be a moving target: Implications of the finding of a native natural enemy, Dorylus orientalis. Chin Sci Bull, 2010, 55: 3743-3745

4 Wang J, Metzner W, Zhu X, et al. Response to seasonal change of insect resources in Changbai Mountain temperate forests by Greater Horseshoe bats. Chin Sci Bull, 2010, 55: 2410-2415

5 Wang G D, Zhu Z H, Shi P, et al. Comparative genomic analysis reveals more functional nasal chemoreceptors in nocturnal mammals than in diurnal mammals. Chin Sci Bull, 2010, 55: 3901-3910

6 Wang X P, Jin W, Yu L, et al. Molecular evolution of stress-response gene Leptin in high-altitude Chinese snub-nosed monkeys (Rhinopithecus genus). Chin Sci Bull, 2010, 55: 4132-4135

7 Chen S Y, Zhang J L, Jia P, et al. Effects of size variation and spatial structure on plastic response of plant height to light competition. Chin Sci Bull, 2010, 55: 1135-1141

8 Tew K S, Meng P J, Lee H J, et al. Dynamics of phytoplankton and picoplankton over a tidal cycle in a subtropical lagoon. Chin Sci Bull, 2010, 55: 2522-2528

9 He J, David I M, Zhang Y P. Gene duplication plays a major role in gene co-option: Studies into the evolution of the motilin/ghrelin family and their receptors. Chin Sci Bull, 2011, 56: 2690-2697

10 Wang Y Y, Yu X B, Li W H, et al. Potential influence of water level changes on energy flows in a lake food web. Chin Sci Bull, 2011, 56: 2794-2802

11 He G, Huang K, Guo S T, et al. Evaluating the reliability of microsatellite genotyping from low-quality DNA templates with a polynomial distribution model. Chin Sci Bull, 2011, 56: 2523-2530

12 Dai Q, Fu J Z. When central populations exhibit more genetic diversity than peripheral populations: A simulation study. Chin Sci Bull, 2011, 56: 2531-2540

13 Pan H J, Shi F L, Chang Z F, et al. Mitochondrial DNA variation analysis suggests extreme low genetic diversity in Guizhou snub-nosed monkeys (Rhinopithecus brelichi). Chin Sci Bull, 2011, 56: 2541-2544

14 Shi L, Wang R W, Zhu L X, et al. Varying coefficient analysis for indeterminate species interactions with non-parametric estimation, exemplifying with a fig-fig wasp system. Chin Sci Bull, 2011, 56: 2545-2552 
15 Xiang Z F, Yu Y, Yang M, et al. Does flagship species tourism benefit conservation? A case study of the golden snub-nosed monkey in Shennongjia National Nature Reserve. Chin Sci Bull, 2011, 56: 2553-2558

16 Li D S, Cui H M, Wang C D, et al. A fast and effective method to perform paternity testing for Wolong giant pandas. Chin Sci Bull, 2011, 56: 2559-2564

17 Zhao S S, Chen X, Wan Q H. Assessment of genetic diversity in the forest musk deer (Moschhus berezovskii) using microsatellite and AFLP markers. Chin Sci Bull, 2011, 56: 2565-2569

18 Zhao Y P, Gong H D, Lu W Q, et al. Growth, photosynthesis and podophyllotoxin accumulation of Dysosma versipellis in response to a light gradient and conservation implications. Chin Sci Bull, 2011,
56: $2570-2575$

19 Zeng C J, Ye Q, Fang S G, et al. Establishment and cryopreservation of liver, heart and muscle cell lines derived from the Chinese alligator (Alligator sinensis). Chin Sci Bull, 2011, 56: 2576-2579

20 Jiang W M, Zhao M S, Fu C X, et al. Study on in vitro regeneration competence of pseudobulb cultures in Changnienia amoena Chien. Chin Sci Bull, 2011, 56: 2580-2585

21 Wang Z H, Yao H, Ding Y Z. Testing reintroduction as a conservation strategy for the critically endangered Chinese alligator: Movements and home range of released captive individuals. Chin Sci Bull, 2011, 56: 2863-2593

22 Fang S G. Does population increase alone ensure the long-term survival of endangered species? Chin Sci Bull, 2011, 56: 2521-2522

Open Access This article is distributed under the terms of the Creative Commons Attribution License which permits any use, distribution, and reproduction in any medium, provided the original author(s) and source are credited. 